\title{
Acute phase response in the primiparous dairy cows after repeated percutaneous liver biopsy during the transition period
}

\author{
P. Jawor' ${ }^{1}$, A. Brzozowska², K. Stoniewski², Z.M. Kowalski ${ }^{3}$, T. Stefaniak ${ }^{1}$ \\ ${ }^{1}$ Department of Immunology, Pathophysiology and Veterinary Preventive Medicine, \\ Wroclaw University of Environmental and Life Sciences, Norwida 31, 50-375 Wroclaw, Poland \\ ${ }^{2}$ Institute of Genetics and Animal Breeding of the Polish Academy of Sciences, \\ Postepu 36A, 05-552 Magdalenka, Jastrzebiec, Poland \\ ${ }^{3}$ Department of Animal Nutrition and Feed Management, University of Agriculture in Krakow, \\ Mickiewicza 24/28, 30-059, Krakow, Poland
}

\begin{abstract}
The aim of this study was to evaluate the acute phase response of dairy cows to repeated liver biopsy in order to estimate the safety of this procedure during the transition period. Liver biopsies (up to $1000 \mathrm{mg}$ of liver tissue) were conducted twice a day, 7 days before expected parturition and 3 days after calving. The number of needle insertions for each biopsy was recorded and was dependent on the amount of obtained tissue. Blood samples were taken on day 7 before expected parturition, then on days 3, 4, 7 and 14 after calving. Body temperature was measured daily in all 30 cows from day 3 until day 14 after calving. The concentrations of haptoglobin, serum amyloid A, fibrinogen and interleukin- 6 were determined in serum and plasma. In $16.7 \%$ of cows, the rectal body temperature rose by $\geq 0.5^{\circ} \mathrm{C}$ on the day after liver biopsy. Although the concentrations of haptoglobin, serum amyloid A and fibrinogen increased significantly after calving $(p<0.01)$, there was no influence of the number of biopsies on the acute phase reaction and repeated biopsy during the transition period had no effect on body temperature. Therefore, the procedure may be regarded as safe for cows during the transition period.
\end{abstract}

Key words: acute phase response, dairy cow, liver biopsy, transition period

\section{Introduction}

The transition from a nonlactating to lactating state is an enormous challenge for dairy cows and it may have a negative impact on health and reproduction. Even subclinical changes can impact behaviour and milk production in dairy cows (Jawor et al. 2012).
Fatty liver is common in early lactating dairy cows and one study showed that more than $50 \%$ of dairy cows had hepatic lipidosis between 6 and 17 days postpartum (Jorritsma et al. 2001). The diagnosis of fatty liver in cows is based on biochemical serum analysis, biopsy and analysis of hepatic tissue as well as ultrasonography (Acorda et al. 1995). Among biochemical pa-

Correspondence to: P. Jawor, e-mail: paulina.jawor@up.wroc.pl 
Table 1. Ingredient and nutrient composition of the diet.

\begin{tabular}{lcc}
\hline \multicolumn{1}{c}{ Ingredient, \% of dry matter } & Before calving & After calving \\
\hline Whole maize silage & 38.2 & 40.7 \\
\hline Haylage & 11.1 & 15.1 \\
\hline High-moisture maize grain silage & 8.2 & 11.7 \\
\hline Barley straw & 15.6 & 1.8 \\
\hline Triticalerain & 14.5 & 16.6 \\
\hline Soybean meal & 5.6 & 6.5 \\
\hline Rapeseed meal & 4.8 & 5.5 \\
\hline Mineral and vitamin suplement & & 0.6 \\
\hline Limestone & 0.5 & $0.6^{2}$ \\
\hline Vitamin suplement & 1.31 & 0.1 \\
\hline Co-bind A-Z ${ }^{3}$ & 0.2 & 0.8 \\
\hline NaHCO & - & \\
\hline Nutrient, \% dry matter & & 14.45 \\
\hline Crude protein & 11.06 & 32.41 \\
\hline Starch, \% DM & 27.99 & 33.60 \\
\hline NDF, \% DM & 41.11 & 19.79 \\
\hline ADF, \% DM & 24.39 & 2.22 \\
\hline ADL, \% DM & 2.99 & \\
\hline
\end{tabular}

${ }^{1}$ cows during dry period: Vitamix KZ (Polmass, Bydgoszcz, Poland)

${ }^{2}$ cows during lactation: Vitamix KW (Polmass, Bydgoszcz, Poland)

${ }^{3}$ mycotoxin binding additive (Delacon Poland)

rameters, concentration of bile acids and albumin, activity of gamma-glutamyl transferase or aminotransferase can be used to evaluate the liver function in cows with fatty liver (Sevnic et al. 2001). However, due to considerable individual variations in these results, they should be interpreted with caution (Sevnic et al. 2001). Therefore, determination of triglyceride content in the liver could be defined exclusively from investigation of liver tissue. Direct organ biopsies enable the study of disease pathogenesis without the need to slaughter animals prior to sampling (Khatun et al. 2013). Although liver biopsy seems to be the best method for diagnosing hepatic lipidosis, percutaneous liver biopsy requires penetration through muscle, peritoneum and viscera, which increases the risk of organ/tissue damage and complications. There is a small risk of bleeding and death due to penetration of hepatic portal blood vessels (Hughes 1962), but it may be underestimated because of the subclinical course of complications. Mortalities associated with clostridial diseases have been reported after liver biopsy (Olander et al. 1966). However, several groups have shown that the collection of repeated liver biopsy samples (10-15 mg) had no effect on the health and DMI of healthy cows when performed during the peak of lactation (Vels et al. 2009, Khatun et al. 2013).
The acute phase response is a reaction of an organism when disturbance of homeostasis (e.g., tissue injury) occurs. In ruminants, acute phase proteins (APP) are sensitive biomarkers which allow early and precise detection of inflammation (Eckersall and Bell 2010). Estimation of APP in cattle has been widely used for monitoring of treatment efficiency in different diseases (Smith et al. 1998, Jawor et al. 2008), monitoring of calf herd health (Ganheim et al. 2007, Furman-Frątczak et al. 2011), or as markers of mastitis (Gronlund et al. 2003), as predictors of retained placenta (Krakowski and Zdzisinska 2007) or metritis (Huzzey et al. 2009).

The aim of this study was to evaluate the acute phase response in cows after repeated liver biopsy to estimate the safety of this procedure during the transition period.

\section{Materials and Methods}

The experimental design was approved by I Local Ethics Commission in Cracow (permission number 99/2009). 


\section{Housing and experimental design}

The study was conducted on the farm belonging to the Institute of Genetics and Animal Breeding of the Polish Academy of Sciences from April 2011 to September 2011. Cows were housed in pre- and postpartum groups in separate pens. The experimental pens provided 10 free-stalls, 8 feed bins (Roughage Intake Control, Insentec B.V., Marknesse, Netherlands) and 2 water troughs (Insentec B.V., Marknesse, Netherlands). All cows were fed the Total Mixed Ration (TMR) once a day. The TMRs were formulated according to the nutrient requirement recommendations of the Institut National de la Recherche Agronomique (2007) for pre- and postpartum period (Table 1). The components of the mixtures were combined in a Data Ranger mixer-wagon (American Calan Inc.) once a day and feeds were immediately delivered to feeding stations. Refusals were removed on the next day. The amount of feed offered to each cow was corrected daily, so that $10-20 \%$ refusals were ensured. Cows in the postpartum period were milked twice a day approximately at 6.00 AM and 5.00 PM.

The evaluation of the acute phase response was conducted in addition to another research projects, studying the effect of glucogenic feed additives on liver transcriptomic profiles in Holstein-Friesian cows in late pregnancy and early lactation. The study was carried out on 34 primiparous cows. The animals were randomly divided into 5 groups. From the $14^{\text {th }}$ day before the expected parturition until the $21^{\text {st }}$ day of lactation, at $10.00 \mathrm{AM}$, cows were drenched with propylene glycol, glycerin or water: 1) GP450 with 450 grams of propylene glycol $(\mathrm{n}=7) ; 2)$ GP900 with 900 grams of propylene glycol $(n=6) ; 3)$ G450 with 450 grams of glycerin $(n=8)$; 4) G900 with 900 grams of glycerin $(\mathrm{n}=6) ; 5) \mathrm{W} 450$ with 450 grams of water (n $=7)$. Since retained placenta (RT) has been shown to have a profound effect on the production of acute phase proteins (Hirvonen et al. 1999), 4 cows with RT were removed from analyses despite finishing the experiment (one cow from each of the following groups: GP450, GP900, W450, G450).

For clarity, the day of parturition was defined as day 0 . All other days were specified relative to calving day; therefore, day -7 should be regarded as day 7 before the expected parturition, whereas days $+3,+4$, +7 and +14 represent 3, 4, 7 and 14 days after calving, respectively.

\section{Liver biopsy}

Liver samples were obtained according to the procedure described by Van den Top et al. (1995). Liver biopsy was carried out by two veterinarians. Re-usable biopsy instruments (a cannula with diameter $0.9 \mathrm{~cm}$, with trocar-tipped $52 \mathrm{~cm}$ length and a $0.8 \mathrm{~cm}$ diameter stainless steel stylet) were used. Biopsies were performed through the $11^{\text {th }}$ intercostal space on the line between elbow and hook. A skin area of $5 \times 5 \mathrm{~cm}$ was clipped and disinfected with ethanol (70\%) and a 3\% solution of iodine. For local anaesthesia, a $2 \%$ solution of Polocainum hydrochloricum $(10 \mathrm{~mL}$ per cow; Biowet Drwalew) was injected s.c. then a stab incision was made and the biopsy needle was inserted in the direction of the opposite elbow to penetrate the liver. When the needle was introduced into the liver, it was turned around its axis to loosen the liver tissue. After the biopsy, the wound was sutured and protected with chlortetracycline hydrochloride (CTC Spray, Eurovet). The biopsies were conducted 7 days before the expected parturition and 3 days after calving. On these days $(-7,+3)$ two biopsies were performed in each animal: one at 11.00 AM and a second one hour later. The number of needle insertions was recorded for each biopsy, since multiple needle insertions were sometimes required in order to obtain a sufficient amount of liver tissue (1000 mg).

\section{Blood collection and analysis}

Prior to the first biopsy, blood samples were collected from the jugular vein and placed in tubes containing serum clot activator (Meus, S.R.L. Italy) and sodium citrate ( $3.8 \%, 1: 9$ solution to blood ratio). The tubes with serum clot activator (serum) were left to clot at room temperature for up to $3 \mathrm{~h}$ and then centrifuged at $1200 \mathrm{~g}$ for $10 \mathrm{~min}$. The tubes containing sodium citrate (plasma) were centrifuged no later than 30 minutes after collection at $1200 \mathrm{~g}$ for $10 \mathrm{~min}$. The resulting serum and plasma samples were aliquoted and frozen at $-20^{\circ} \mathrm{C}$ for later analysis. Blood samples were collected on day -7 (deviation from 0 to -11 , as predicting the exact day of calving was impossible), then $+3,+4$ (in 4 cases +5 ), +7 (in 5 cases +6 ) and +14 . In days without biopsy, blood was taken at 10.00 AM after the drenching. Deviations in the day of blood collection arose from factors unrelated to the experiment. The number of obtained samples was large enough so these deviations should have a minor influence on the results. A total of 144 serum samples were collected from 30 cows ( 2 samples from day -7 and 4 samples from day +4 were missed).

The haptoglobin $(\mathrm{Hp})$ concentration was determined using the guaiacol method (Jones and Mould 1984) with human haptoglobin Hp 2-2 (Sigma, H9762) as a standard. The Hp concentration was determined in serum for all time points. The concentra- 
Table 2. Mean \pm SE of haptoglobin ( $\mathrm{Hp}$ ), serum amyloid A (SAA), fibrinogen ( $\mathrm{Fb}$ ) and interleukin 6 (IL-6) during the transition period. Data marked by different letters were statistically different at $p<0.01$.

\begin{tabular}{|c|c|c|c|c|c|}
\hline & & & relative to ca & & \\
\hline & -7 & +3 & +4 & +7 & +14 \\
\hline $\mathrm{Hp}(\mathrm{g} / \mathrm{L})$ & $0.20 \pm 0.07^{\mathrm{AC}}$ & $0.84 \pm 0.12^{\mathrm{B}}$ & $0.68 \pm 0.09^{\mathrm{B}}$ & $0.41 \pm 0.09^{\mathrm{AB}}$ & $0.13 \pm 0.08^{\mathrm{C}}$ \\
\hline SAA $(\mathrm{mg} / \mathrm{L})$ & $34.7 \pm 5.8^{\mathrm{A}}$ & $74.8 \pm 5.3^{\mathrm{B}}$ & $80.1 \pm 7.0^{\mathrm{B}}$ & $57.8 \pm 5.2^{\mathrm{AB}}$ & ND \\
\hline $\mathrm{Fb}(\mathrm{g} / \mathrm{L})$ & $8.2 \pm 0.5^{\mathrm{A}}$ & $11.2 \pm 0.6^{\mathrm{B}}$ & $10.6 \pm 0.6^{\mathrm{B}}$ & $10.9 \pm 0.5^{\mathrm{B}}$ & $9.6 \pm 0.5^{\mathrm{AB}}$ \\
\hline IL-6 (pg/mL) & $35.1 \pm 35.1$ & $78.0 \pm 53.5$ & $60.1 \pm 39.6$ & ND & ND \\
\hline
\end{tabular}

ND - not determined

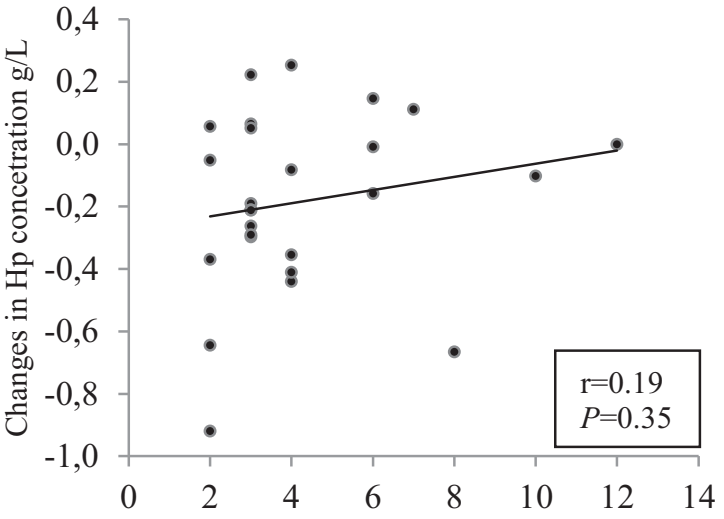

A number of needle insertions on day +3

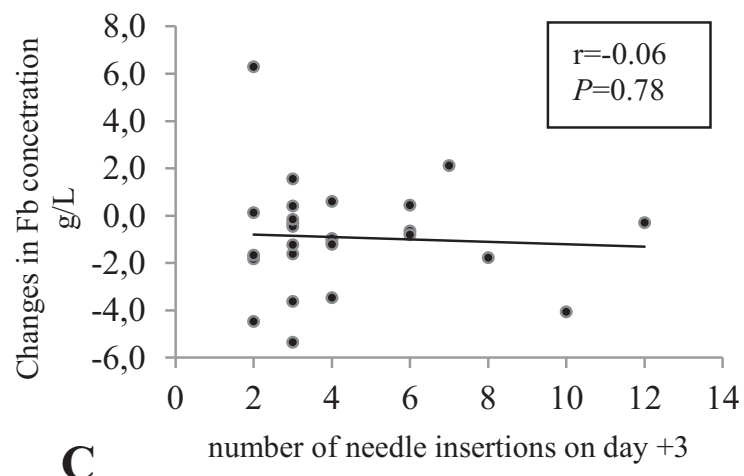

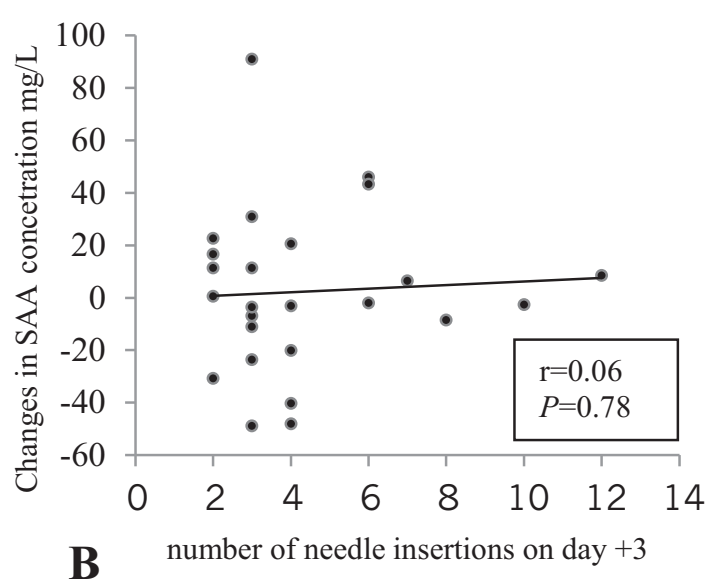

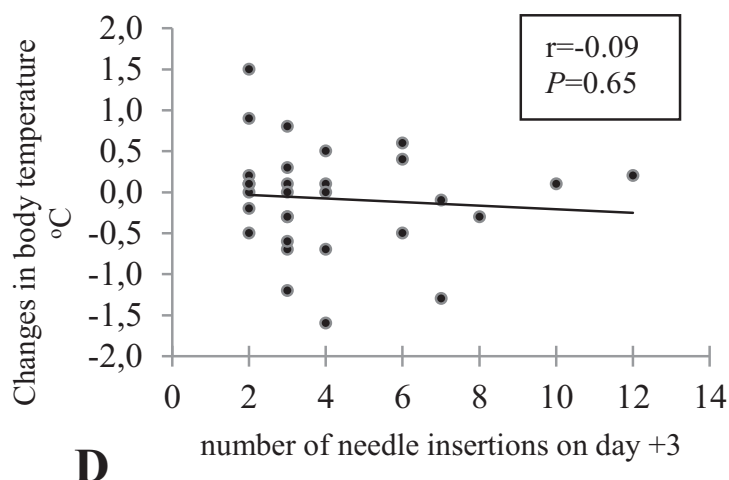

Fig. 1. Correlation between the number of needle insertions on day +3 and the change in: A) haptoglobin concentration, B) serum amyloid A concentration, C) fibrinogen concentration, D) body temperature between days +4 and +3 . Trend line was marked as a solid line.

tion of serum amyloid A (SAA) was determined by multispecies ELISA (Tridelta Development, TP 802, Intra-Assay and Inter-Assay $\mathrm{CV} \%$ for Bovine was $7.5 \%$ and $12.1 \%$, respectively). SAA concentration was determined for all time points, except for day +14 . The plasma fibrinogen $(\mathrm{Fb})$ concentration was measured using the prothrombin-time-derived method with a coagulometer CoagChrom 3003 and reagents (Bio-Ksel, Poland) according to the manufacturer's instructions. The standard curve was made from 50 pooled plasma samples from healthy adult cattle. The $\mathrm{Fb}$ concentration was determined for all time points.

Interleukin 6 (IL-6) concentrations were determined by ELISA (USCN, Life Science Inc., E90079Bo, Intra-Assay and Inter-Assay CV \% for Bovine was $<10 \%$ and $<12 \%$, respectively) in serum samples from group $\mathrm{W} 450$ on days $-7,+3$ and +4 .

The detection limits for $\mathrm{Hp}, \mathrm{SAA}, \mathrm{Fb}$ and IL-6 were $0.1 \mathrm{~g} / \mathrm{L}, 9.4 \mathrm{mg} / \mathrm{L}, 0.1 \mathrm{~g} / \mathrm{L}$ and $124.8 \mathrm{pg} / \mathrm{mL}$, 
respectively. Additionally, after calving, the rectal body temperature was measured at 10.00 AM daily from day +3 until +14 , in all cows.

\section{Statistical Methods}

For statistical analysis STATISTICA 10 software and Microsoft Excel 2010 were used. The groups with different gluconeogenic precursors were compared using ANOVA Kruskal-Wallis. Since no significant differences in APP concentrations were found between groups on particular days, cows were merged into one group, and the differences between days relative to calving were compared using ANOVA Friedman followed by a Bonferoni-Dunn test. The Pearson's correlation coefficient was calculated between the number of needle insertions during the biopsies and the relative change in acute phase proteins or temperature between days +4 and +3 .

\section{Results}

The mean milk production $(\mathrm{kg} / \mathrm{d} / \mathrm{cow} \pm \mathrm{SD})$ in the first 4 weeks after calving was not significantly different between groups $(20.9 \pm 4.3 ; 19.2 \pm 4.2 ; 21.7$ $\pm 5.0 ; 18.7 \pm 3.7 ; 21.6 \pm 4.7$ for cows drenched with either propylene glycol 450 or 900 , glycerin 450 or 900 gram and water 450 gram respectively). The concentrations of Hp, SAA, Fb and IL-6 are shown in Table 2. The concentration of $\mathrm{Hp}$ increased after calving on days +3 and +4 and was significantly higher than before parturition. The lowest Hp concentration occurred on day +14 and this value was significantly different from the concentrations on days $+3,+4$ and +7 . The Hp concentration decreased after postpartum biopsy and was no longer significantly different from day -7 by days +7 and +14 . Similarly, the concentration of SAA increased on day +3 and was significantly different from the concentration prior to parturition. The significant increase persisted until day +4 , and then the SAA concentration decreased and was no longer significantly different by day +7 . After the second liver biopsy, the SAA concentration increased on day +4 , but this increase was not statistically significant. The Fb concentration increased after calving and was significantly different from day -7 up until day +7 . Postpartum liver biopsy did not affect the Fb concentration, which was not significantly different on day +14 as compared to day -7 . Although the mean concentration of IL- 6 increased on day +3 , the difference comparing to day -7 was not significant. On day +4 , the IL-6 concentration decreased.
The number of needle insertions on day +3 had no influence on the relative change in $\mathrm{Hp}$, SAA or $\mathrm{Fb}$ concentrations between days +4 and +3 (Fig. 1 A, B, $\mathrm{C}$, respectively). There were no significant correlations between any of these APP concentrations and the number of needle insertions.

The mean body temperature of cows from day +3 until +14 were within the reference range (from 38.9 to $39.2^{\circ} \mathrm{C}$ ). During this period, increased temperature (over $39.5^{\circ} \mathrm{C}$ ) was found in 19 cows and three of them were treated with antibiotics (Pen-Strep, ScanVet Poland). Only three cows had an increased temperature for three consecutive days or longer. In 5 cows $(16.7 \%)$ the temperature on the next day after the biopsy increased by $\geq 0.5^{\circ} \mathrm{C}$. In 16 cows, the body temperature did not change after the biopsy. The correlation between the number of needle insertions and the change in body temperature between days +4 and +3 was not statistically significant $(P=0.65$; Fig. $1 \mathrm{D})$.

\section{Discussion}

Normal calving triggers the acute phase response. In our study, there was an increase in the concentration of APP after calving. In previous studies (Uchida et al. 1993, Chan et al. 2010), Hp and SAA concentrations were shown to increase in healthy cows after calving and the highest concentrations of $\mathrm{Hp}$ and SAA occurred 2-3 days later. Due to the lack of a control group containing cows that were not biopsied on day -7 , it is difficult to associate this increase only with parturition. However, since liver biopsy on day +3 did not cause an increase in the concentration of APP on days +7 and +14 , we may conclude that the total increase between days -7 and +3 was very probably triggered by parturition. In our study, the mean $\mathrm{Hp}$ concentration following parturition was higher than that presented for healthy cows $(0.58 \pm 0.12 \mathrm{~g} / \mathrm{L})$ in the study of Huzzey et al. (2009), but lower than in cows with metritis $(1.10 \pm 0.43 \mathrm{~g} / \mathrm{L})$ as reported by Chan et al. (2010). Although no cows in the present study were diagnosed with metritis, the mean SAA concentration on day +3 was similar to that of cows which developed puerperal metritis in the study by Chan et al. (2010). In their study, Chan et al. (2010) reported that healthy cows had lower SAA concentrations than cows with metritis (66 vs. $73 \mathrm{mg} / \mathrm{L}$ measured between 0-3 days postpartum), but these differences were not statistically significant. In the present study, the concentration of SAA on day +4 was slightly lower than Chan et al. (2010) metritis group $(85 \mathrm{mg} / \mathrm{L})$, but still higher than in their healthy cows $(48 \mathrm{mg} / \mathrm{l})$. This discrepancy could be due to the differences in sample collection between the studies, as 
Chan et al. (2010) measured SAA concentrations between 4-7 days postpartum whereas our measurements were recorded on days +4 and +7 separately. The differences between the values may also be due to different methods used for the estimation of SAA. Therefore, it seems that in interpreting the value of APP in cattle, the absolute concentration is not as important as the patterns of fluctuation (increase or decrease). This argument is strengthened by individual variation in APP concentrations between cows, interindividual variability in the physiologic acute phase response and the fact that the ability to produce SAA and Hp may be an innate characteristic of the individual (Jacobsen et al. 2004, Humblet et al. 2006).

In our study, the mean $\mathrm{Fb}$ concentration was above the previously reported reference range (Wood and Quiroz-Rocha 2010). After calving, Fb concentrations significantly increased and the values were similar to those of cows with limb diseases before the treatment (Jawor et al. 2008). However, the higher concentration in the present study probably resulted from differences in the methods used for $\mathrm{Fb}$ estimation, as in the study of Jawor et al. (2008) Fb was measured using the heat precipitation method. Methods which measure clotting time cannot be used interchangeably with heat precipitation methods, as due to different principles used to estimate fibrinogen concentration no correlation between the results of these two techniques was observed (Athanasiou et al. 2013).

In order to evaluate the influence of repeated liver biopsy on the acute phase reaction the correlation between the number of needle insertions on day +3 and the change in APP concentrations between days +4 and +3 was calculated. The lack of correlation between the number of needle insertions and changes in $\mathrm{Hp}, \mathrm{SAA}, \mathrm{Fb}$ concentrations shows that trauma induced by skin incision and liver sampling through a biopsy needle did not affect the acute phase response or the production of APP. Similar results were shown by Vels et al. (2009), who performed biopsies on a smaller number of animals later in lactation (9-12 wk after parturition) using a minimally invasive biopsy technique (one sampling per day, maximum 6 biopsy samplings in one cow). They found no differences in APP response, dry matter intake or clinical signs such as heart rate and respiratory rate, white blood cell, somatic cell count or cytokine responses, between cows biopsied three versus six times (Vels et al. 2009).

The lack of increase in IL- 6 concentration between days +3 and +4 after liver biopsy seems to be in accordance with the results of Vels et al. (2009), who showed no increase in the expression of IL-6 mRNA (necessary for production of IL-6) in liver. No increase in the expression of IL-6, the major cytokine involved in inducing the acute phase reaction, explains why no increase in expression of the other examined APP was found. We cannot exclude that the limited number of serum samples affected the IL-6 results and that with a higher number of animals, the IL-6 results might be different. Contrary to our results, in a study by Ishikawa et al. (2004), the postpartum IL-6 concentration in cows was lower than the prepartum levels. Moreover, the IL- 6 concentration was higher on day $-5(2.0 \pm 0.2 \mathrm{ng} / \mathrm{mL})$ and on day +3 $(1.6 \pm 0.1 \mathrm{ng} / \mathrm{mL})$ than in our study. These discrepancies were probably the result of different assays used for IL-6 estimation. Different detection methods, and the lack of references for IL-6 concentrations in cattle, impede the comparison of absolute IL-6 levels between studies (Jawor et al. 2013).

In our study only a small percentage $(16.7 \%)$ of cows had an increased temperature after biopsy, but in the study by Vels et al. (2009) cows biopsied six times tended to have $0.2^{\circ} \mathrm{C}$ higher body temperature in comparison to those biopsied three times. We did not observe any correlation between changes in body temperature and the number of needle insertions, which indicates that the procedure is safe for cows after parturition.

Even though cows are locally anesthetized for biopsy, this intervention has been shown to affect dry matter intake and pain-related behaviour in cows for up to 19 hours (Mølgaard et al. 2012). The results of our study show that this procedure is safe and does not induce any additional generalized immune response in the form of the acute phase reaction. Therefore, we suggest that biopsy may be safely used for the diagnosis of fatty liver during the transition period. The authors are aware that the absence of a control group containing cows without liver biopsies makes it difficult to draw strong conclusions from our study. However, we believe that this study is the first to show changes in APP after repeated biopsies during the transition period and the results provide a better understanding of this process. Since the results of this study showed no significant effects on the systemic production of $\mathrm{Hp}$, SAA, Fb, IL-6 or inner body temperature, indicating that repeated liver biopsy during the transition period may be considered a safe procedure, and may be effectively used for diagnosis of fatty liver without undue concern for animal health.

\section{Acknowledgements}

This study was supported by funds of Wroclaw University of Environmental and Life Sciences, Faculty of Veterinary Medicine, project no 1/H/2011. Publication supported by Wrocław Center of Biotech- 
nology, program Leading National Research Center (KNOW) for the years 2014-2018.

\section{References}

Acorda JA, Yamada H, Ghamsari SM (1995) Comparative evaluation of fatty infiltration of the liver in dairy cattle by using blood and serum analysis, ultrasonography, and digital analysis. Vet Q 17: 12-14.

Athanasiou LV, Petanides TA, Chatzis MK, Saridomichelakis MN (2013) Measurement of fibrinogen concentration in the plasma of dogs: a comparison between heat precipitation and modified thrombin clotting time method. Am J Anim Vet Sci 8: 73-78.

Chan JP, Chang CC, Hsu WL, Liu WB, Chen TH (2010) Association of increased serum acute-phase protein concentrations with reproductive performance in dairy cows with postpartum metritis. Vet Clin Pathol 39: 72-78.

Eckersall PD, Bell R (2010) Acute phase proteins: Biomarkers of infection and inflammation in veterinary medicine. Vet J 185: 23-27.

Furman-Fratczak K, Rzasa A, Stefaniak T (2011) The influence of colostral immunoglobulin concentration in heifer calves' serum on their health and growth. J Dairy Sci 94: 5536-5543.

Ganheim C, Alenius S, Presson Waller K (2007) Acute phase proteins as indicators of calf herd health. Vet J 173: 645-651.

Gronlund U, Hulten C, Eckersall PD, Hogarth C, Persson Waller K (2003) Haptoglobin and serum amyloid A in milk and serum during acute and chronic experimentally induced Staphylococcus aureus mastitis. J Dairy Res 70: 379-386.

Hirvonen J, Huszenicza G, Kulcsgr M, Pyorala S (1999) Acute-phase response in dairy cows with acute postpartum metritis. Theriogenology 51: 1071-1083.

Hughes JP (1962) A simplified instrument for obtaining liver biopsies in cattle. Am J Vet Res 23: 1111-1113.

Humblet MF, Guyot H, Boudry B, Mbayahi F, Hanzen C, Rollin F, Godeau JM (2006) Relationship between haptoglobin, serum amyloid A, and clinical status in a survey of dairy herds during a 6-month period. Vet Clin Pathol 35: 188-193.

Huzzey JM, Duffield TF, LeBlanc SJ, Veira DM, Weary DM, von Keyserlingk MA (2009) Short communication: Haptoglobin as an early indicator of metritis. J Dairy Sci 92: 621-625.

Institut National de la Recherche Agronomique (2007) Alimentation des bovins, ovins et caprins. Besoins des animaux - valeurs des aliments, Tables INRA 2007. 1st ed., Quae, Versailles Cedex.

Ishikawa Y, Nakada K, Hagiwara K, Kirisawa R, Iwai H, Moriyoshi M, Sawamukai Y (2004) Changes in interleukin-6 concentration in peripheral blood of pre- and post-partum dairy cattle and its relationship to postpartum reproductive diseases. J Vet Med Sci 66: 1403-1408.

Jacobsen S, Andersen PH, Toelboell T, Heegaard PMH (2004) Dose dependency and individual variability of the lipopolysaccharide-induced bovine acute phase protein response. J Dairy Sci 87: 3330-3339.

Jawor PE, Huzzey JM, LeBlanc SJ, von Keyserlingk MAG (2012) Associations of subclinical hypocalcemia at calving with milk yield, and feeding, drinking, and standing behaviors around parturition in Holstein cows. J Dairy Sci 95: 1240-1248

Jawor P, Stefaniak T, Sołtysiak Z, Dzimira S, Bednarski $M$ (2013) Salmonella enterica serovar Stanley intrauterine infection in a stillborn calf - case report. Acta Vet Brno 82: 363-367.

Jawor P, Steiner S, Stefaniak T, Baumgartner W, Rzasa A (2008) Determination of selected acute phase proteins during the treatment of limb diseases in dairy cows. Vet Med (Praha) 53: 173-183.

Jones GE, Mould DL (1984) Adaptation of the guaiacol (peroxidase) test for haptoglobins to a microtitration plate system. Res Vet Sci 37: 87-92.

Jorritsma R, Jorritsma H, Schukken YH, Bartlett PC, Wensing $\mathrm{T}$, Wentink GH (2001) Prevalence and indicators of post partum fatty infiltration of the liver in nine commercial dairy herds in The Netherlands. Livest Prod Sci 68: 53-60.

Khatun M, Szrensen P, Ingvartsen KL, Bjerring M, Rzntved CM (2013) Effects of combined liver and udder biopsying on the acute phase response of dairy cows with experimentally induced E. coli mastitis. Animal 7: 1721-1730.

Krakowski L, Zdzisińska B (2007) Selected cytokines and acute phase proteins in heifers during the ovarian cycle course and in different pregnancy periods. Bull Vet Inst Pulawy 51: 31-36.

Mzlgaard L, Damgaard BM, Bjerre-Harpzth V, Herskin MS (2012) Effects of percutaneous needle liver biopsy on dairy cow behaviour. Res Vet Sci 93: 1248-1254.

Olander HJ, Hughes JP, Biberstein EL (1966) Bacillary hemoglobinuria: induction by liver biopsy in naturally and experimentally infected animals. Pathol Vet 3: 421-450.

Sevinc M, Basoglu A, Birdane FM, Boydak M (2001) Liver function in dairy cows with fatty liver. Revue Med Vet 152: 297-300.

Smith BI, Donovan GA, Risco CA, Young CR, Stanker LH (1998) Serum haptoglobin concentrations in Holstein dairy cattle with toxic puerperal metritis. Vet Rec 142: 83-85.

Uchida E, Katoh N, Takahashi K (1993) Appearance of haptoglobin in serum from cows at parturition. $\mathrm{J}$ Vet Med Sci 55: 893-894.

Van den Top AM, Wensing T, Geelen MJ, Wentink GH, van't Klooster AT, Beynen AC (1995) Time trends of plasma lipids and enzymes synthesizing hepatic triacylglycerol during postpartum development of fatty liver in dairy cows. J Dairy Sci 78: 2208-2220.

Vels L, Rzntved CM, Bjerring M, Ingvartsen KL (2009) Cytokine and acute phase protein gene expression in repeated liver biopsies of dairy cows with a lipopolysaccharide-induced mastitis. J Dairy Sci 92: 922-934.

Wood D, Quiroz-Rocha GF (2010) Normal hematology of Cattle. Schalm's Veterinary Hematology, 6th ed., Wiley-Blackwell, Iowa. 